\title{
EXPERIMENTAL AND THEORETICAL INVESTIGATIONS OF PALLET RACKS CONNECTIONS
}

\author{
Lucjan Ślęczka and Aleksander Kozłowski \\ Rzeszów University of Technology, Department of Building Structures, W. Pola 2, 35-959 Rzeszów, Poland \\ Fax.: +48-17-8542974 \\ (Corresponding author: E-mail: sleczka@prz.rzeszow.pl)
}

Received: 16 November 2006; Revised: 24 January 2007; Accepted: 5 February 2007

\begin{abstract}
Steel storage pallet racks are three-dimensional framed structures, similar to multi-storey building structures. They are widely used for the storage of different types of materials. To provide the easy accessibility to stored products, pallet racks are not braced in down-aisle direction. The only source of the stiffness required for down-aisle stability is the stiffness of the connections between columns and beams, and the stiffness of the column bases. Connections between columns and beams are realized by means of different types of mechanical devices (tabs, hooks etc) without the need of using bolts and welds. Such joints have non-linear $M-\phi$ characteristic. Most of the recent design codes and papers recommend experimental tests of beam-to-column connections to obtain semi-rigid joint characteristics that can be applied in the global analysis. The aim of this paper is to present application of the component method to assess main joint properties, i.e. the moment resistance and initial stiffness of storage rack joints. Results obtained using developed model are compared with the test results.
\end{abstract}

Keywords: Storage pallet racks, component method, semi-rigid connection, experimental tests

\section{INTRODUCTION}

Steel pallet racks are regular, 3D multi-storey, multi-bay structures, used in industry and warehouses for the storage of palletised goods (Fig. 1). They are realized by using cold-formed steel profiles. Design analysis of such structures is carried out on 2D sub-assemblies, separately in the cross- and down-aisle directions. Stability in the cross-aisle direction is provided by bracings. To provide the easy accessibility to stored products, pallet racks are not braced in down-aisle direction. Because of lack of bracings in the down-aisle direction, structural analysis is carried out by adopting a semi-continuous sway frame model, i.e. unbraced frame with semi-rigid joints. Analysis of such structures were described in a few papers (Abdel-Jaber et al [1], Beale and Godley [2], Bernuzzi and Castiglioni [3], Freitas et al [4], Godley et al. [5], Peköz and Rao [6], The et al. [7])

Connections between columns and beams are realized in such structures by means of different types of mechanical devices such tabs, hooks etc, without the need of using bolts and welds. These joints have non-linear $M-\phi$ characteristic (Baldassino and Zandonini [8], Baldassino and Bernuzzi [9], Markazi et al. [10], Markazi et al. [11]. Most of the recent design codes and papers, recommend an experimental-theoretical design approach and require experimental tests of beam-to-column connections to obtain semi-rigid joint characteristics that can be applied in the global analysis. Such experimental tests were conducted for one of the commercially available steel racks system in Poland. Observation of joint behaviour during tests suggests the possibility of using the component method to evaluate the main joint properties i.e. moment resistance and initial stiffness. The aims of the paper are to present model of the component method for the investigated rack joints and compare results between the tests and the component modelling. 


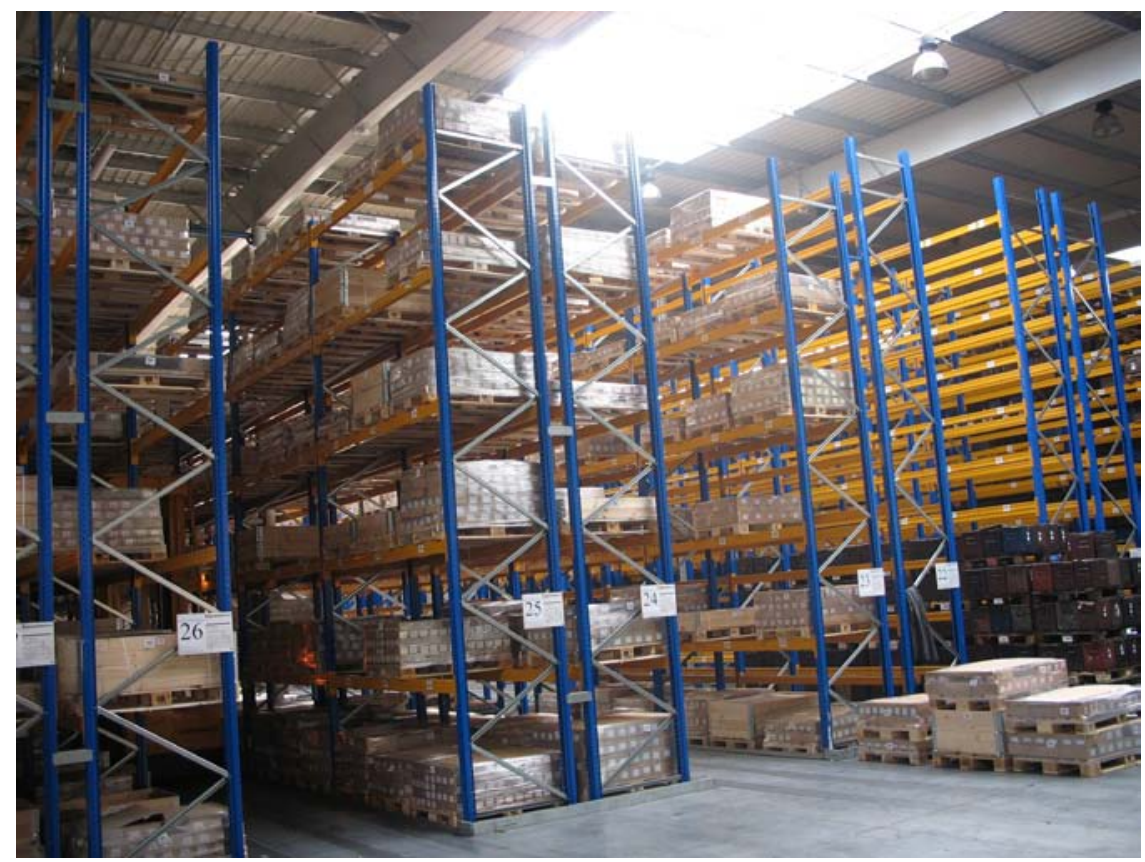

Figure 1. Typical Pallet Racks Configuration

\section{EXPERIMENTAL PROCEDURE AND THE TEST RESULTS}

A sketch of tested beam-to-column connection with its dimensions is shown in Figure 2. The joint consists of a beam-end connector with tabs, made of a 4-mm thick cold-formed angle, welded to each end of the beam. The leg of the angle with tabs is in contact with column web after assembly, while there is a 2-mm gap between the second leg, perpendicular to the column web.

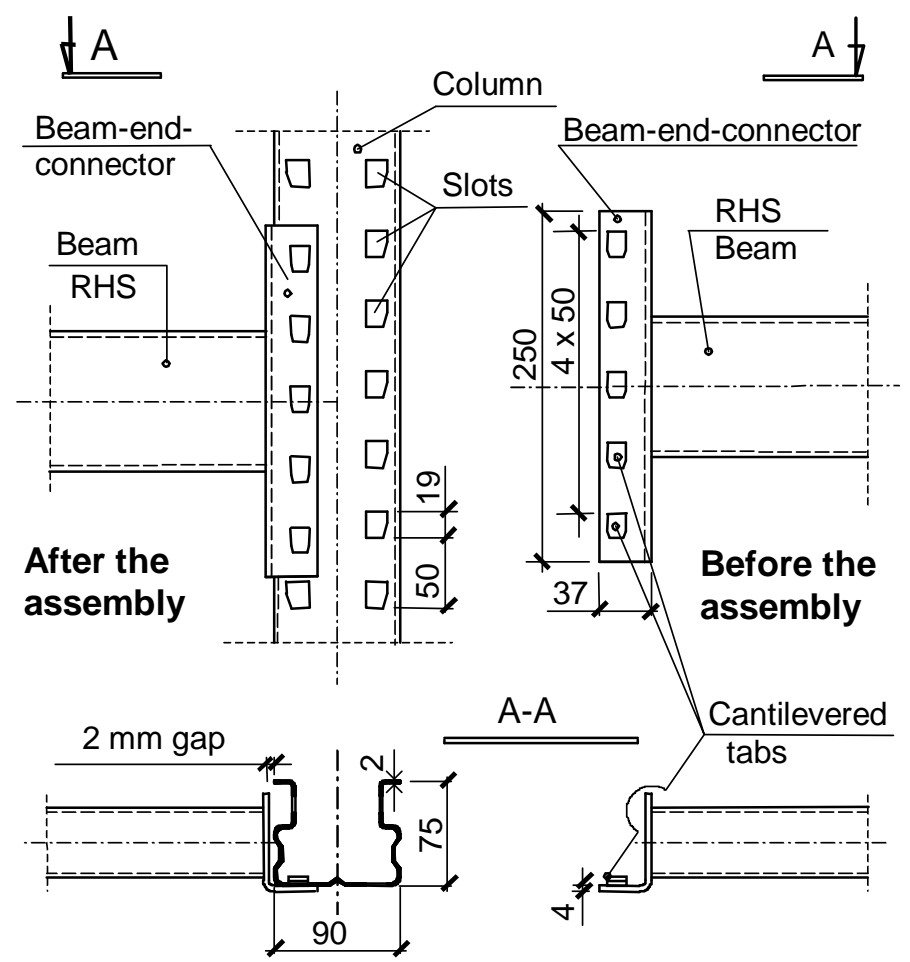

Figure 2. Dimensions of Tested Joint 
Recommendations (Institute of Logistics and Warehousing [12]) suggest two possible ways of testing to evaluate the joint behaviour. One is bending test on isolated beam-column connection, second is portal test, where the frame, composed of two columns and one beam, is loaded by vertical and horizontal forces. Bending tests on isolated connections were conducted for analysed connections. Research program is summarized in Table 1. The main aim of experimental tests was to obtain moment-rotation characteristics of tested joints and also the observation of behaviour of joint components under loading and finally failure modes. Figure 3 shows the general layout of the tests. Tests were carried out on five full-scale joint groups. Two groups ("D" and "F") consisted of single-sided joints of external columns. Other three groups (group "B", "C" and "E”) were doublesided connections of beams to internal columns. Every tested group had the same connector and column section, while the size of the beam was different in each group. To prevent lateral movements whilst loading, both column and beams elements were doubled and connected to each other. Distance $e_{1}=e_{2}$ was established so, as the force $F$ equal to $25 \%$ of shear capacity of connection could produce ultimate bending moment value with tolerance $\pm 30 \%$ (Institute of Logistics and Warehousing [12]). In order to assess end rotations of the beams, two dial gauges were used at each beam. End rotations of beam were obtained as the relative gauges displacements divided by the separation between them. Because of large stiffness of beam, no correction factor was used for the calculation of the joint rotation (with regard to deflection of the cantilevered beam). In one sided-tests, rotations of the connection was obtained by subtracting the rotation of the column from the rotation of the beam. Testing procedures, instrumentation and detailed test results of analysed joints can be found in (Kozłowski and Ślęczka [13]).

Table 1. Research Program

\begin{tabular}{|l|c|c|c|}
\hline Symbol & $\begin{array}{c}\text { Number of } \\
\text { specimens }\end{array}$ & Type of tests & $\begin{array}{c}\text { Type of } \\
\text { beam (RHS) }\end{array}$ \\
\hline Group “B” & 6 & Bending tests, internal column & $100 \times 50 \times 3$ \\
\hline Group “C” & 6 & Bending tests, internal column & $80 \times 40 \times 3$ \\
\hline Group "D” & 5 & Bending tests, external column & $100 \times 50 \times 3$ \\
\hline Group "E" & 6 & Bending tests, internal column & $120 \times 60 \times 3$ \\
\hline Group "F" & 6 & Bending tests, external column & $120 \times 60 \times 3$ \\
\hline
\end{tabular}
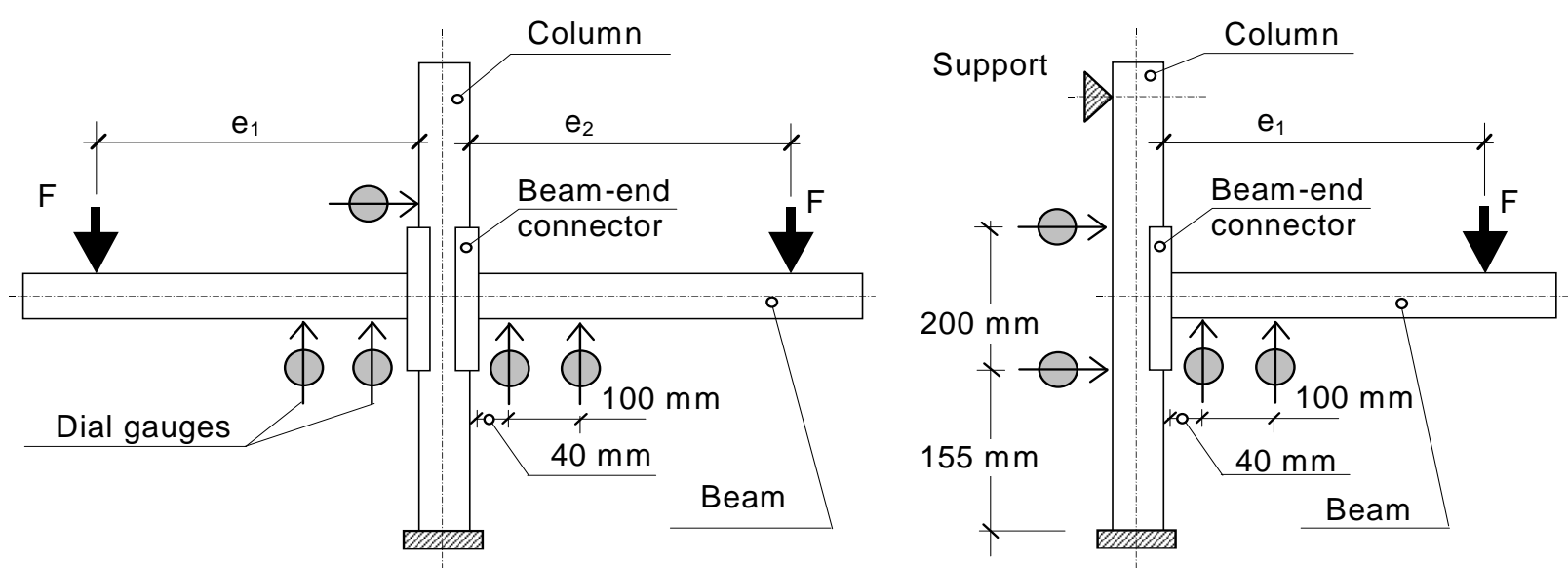

Figure 3. General Layout of Double-sided (Internal Column) and One-sided (External Column) Tests

The main test results are summarized in Table 2 and Table 3. Every tested group has consisted of six specimens. Values presented in Tables 2 and 3 are arithmetic mean values. The plastic flexural resistance $M_{p l, \text { exp }}$ was obtained as a point of intersection of a straight line representing initial 
stiffness $S_{j, \text { ini }}$, with the line of slope $0,1 S_{j, \text { ini }}$, which is tangent to the non-linear part of the curve obtained in test (Fig. 4).

Table 2. Material Properties

\begin{tabular}{|l|c|c|c|}
\hline \multicolumn{1}{|c|}{ Part of the joint } & Yield stress, [MPa] & Ultimate stress, [MPa] & Elongation, [\%] \\
\hline Column & 384.2 & 431.4 & 30.7 \\
Connector & 346.6 & 403.3 & 37.2 \\
Beam & 404.7 & 433.3 & 36.9 \\
\hline
\end{tabular}

Table 3. Main Test Results of Joints

\begin{tabular}{|l|c|c|c|}
\hline & $\begin{array}{c}\text { Initial rotational } \\
\text { stiffness } S_{j, i n i} \\
{[\mathrm{kNm} / \mathrm{rad}]}\end{array}$ & $\begin{array}{c}\text { Plastic flexural } \\
\text { resistance } M_{p l, \exp }\end{array}$ & $\begin{array}{c}\text { Ultimate flexural } \\
\text { resistance } M_{u, \exp } \\
{[\mathrm{kNNm}]}\end{array}$ \\
\hline Group “B” & 139,40 & 3,19 & 3,90 \\
Group “C” & 116,70 & 2,36 & 3,27 \\
Group “D” & 71,35 & 3,10 & 3,58 \\
Group “E” & 123,06 & 3,20 & 3,73 \\
Group “F” & 96,15 & 3,37 & 3,86 \\
\hline
\end{tabular}

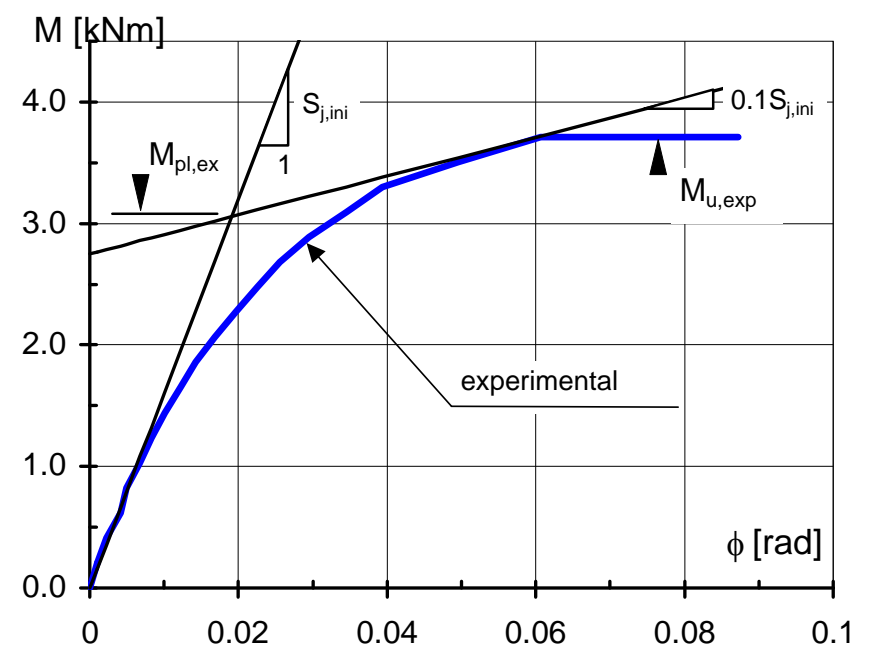

Figure 4. Experimental $M-\phi$ Curve, Specimen B5

\section{APPLICATION OF COMPONENT METHOD TO MODELLING OF PALLET RACK CONNECTIONS}

The component method is now one of the most effective methods to analyze and predict the rotational behaviour of different types and different configurations of connections. It is mainly used in case of steel joints made from hot rolled sections (EN 1993-1-8 [14]) and composite joints (EN 1994-1-1 [15]), but recently has also found other applications (Fink et al. [16]).

The application of the component method is usually performed in three stages. The first stage is the identification of components in the analyzed joint, where the complex joint is subdivided into parts. The second stage is the prediction, for each identified component, of its individual initial stiffness, strength and often deformation capacity. The behaviour of each component is described by a bilinear relationship between displacement and force. Components that do not affect the stiffness of the joint are modelled as rigid-plastic, while other components are modelled as elasto-plastic 
elements. The third stage is the evaluation of flexural strength and rotational stiffness of the whole joint. In this stage, the lever arms should also be predicted for every group of components. Behaviour of connection is then predicted by analysing group of springs with axial stiffness, joined in series or in parallel.

\subsection{Identification of Components}

In the case of analyzed storage rack joint, the following components can be identified:

\subsubsection{Column web in tearing}

A part of the column web situated between the slot and the flange of the column is subjected to a distributed load transmitted by the tabs in the connector. Fixed-ended beam of a span equal to the height of the slot, loaded by contact stresses can be used to model the behaviour of this component (Fig. 5). The resistance of the component depends mainly on shear stresses. This component is active only in a tensioned part of the joint.

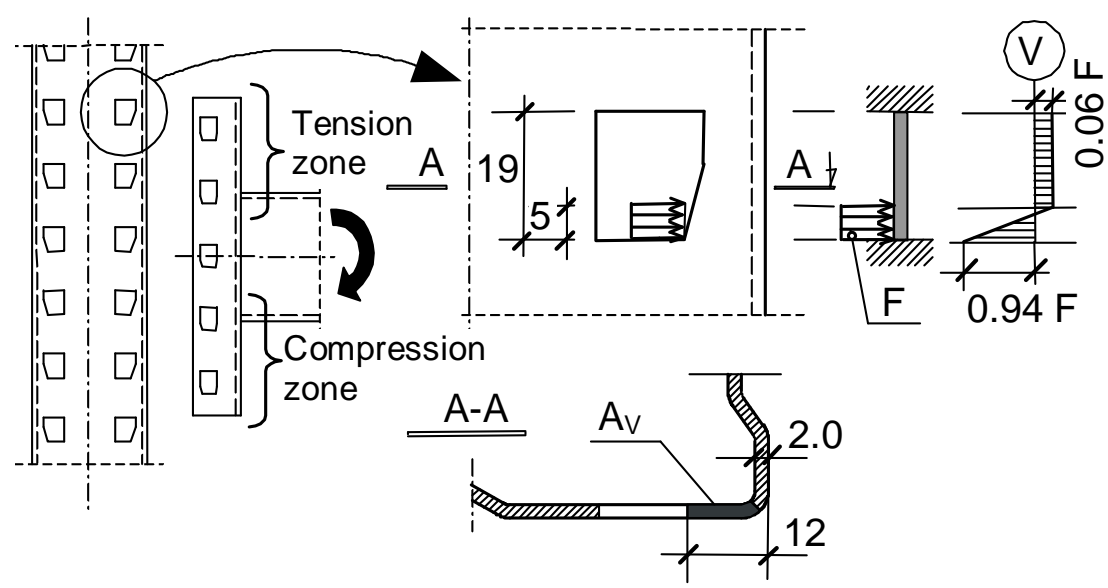

Figure 5. Model to Determine the Resistance and Stiffness of Column Web in Tearing

According to Figure 5, the resistance $F_{c w \text {,tear }}$ can be obtained considering the relationship:

$0.94 F_{c w, t e a r}=A_{v} \frac{1}{\sqrt{3}} f_{\text {u.cw }}$

where $F_{c w \text {, tear }}$ - resistance of column web in tearing; $A_{V}$ - shear area of part of column web, as indicated in Figure 5 and $F_{u, c w}$ - ultimate tensile stress of column web. From Equation 1 the resistance of column web in tearing can be calculated as $F_{c w}$, tear $=6,36 \cdot 10^{3} \mathrm{~N}$.

The initial stiffness of spring element modelling column web in tearing $k_{c w, t e a r}$ is given by general rule:

$k_{c w, t e a r}=\frac{F}{\delta}$

where $\delta$-deflection of the beam caused by bending and shear deformation under load $F$. Using deflection equations for beam shown in Figure 5, it can be found that $k_{c w, t e a r}=5599 \cdot 10^{2} \frac{\mathrm{N}}{\mathrm{mm}}$. The effect of tearing of the column web observed during the tests is shown in Figure 6. 


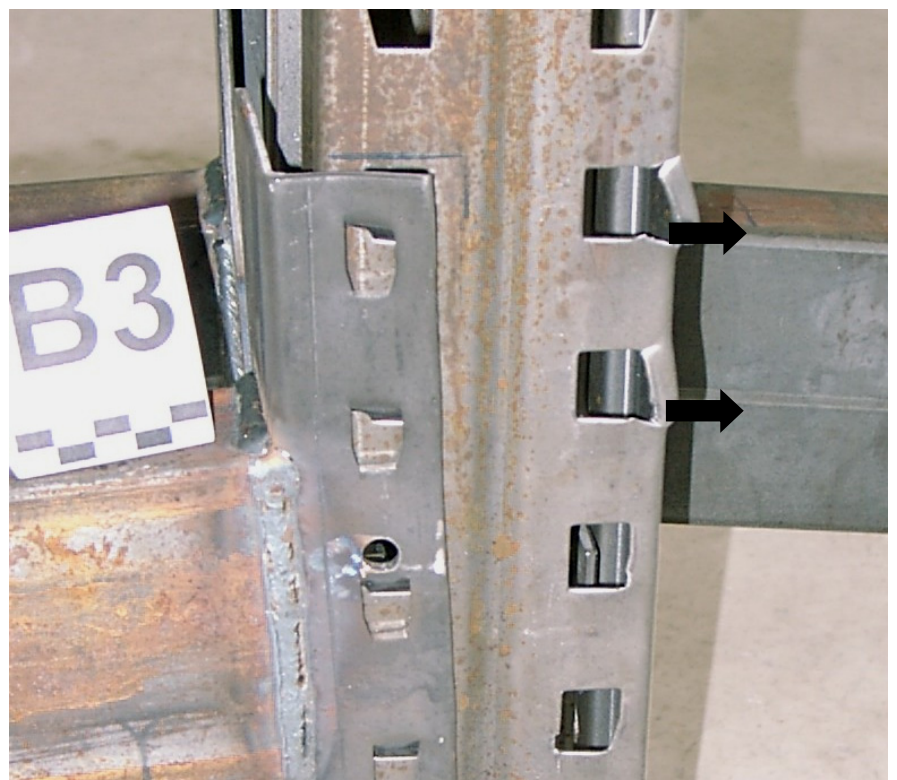

Figure 6. Tearing of the Column Web Observed during the Tests

\subsubsection{Column web in bearing}

This component is active both in the tension and compression zones of the joint (Fig. 7). The resistance of the column web in bearing $F_{c w, b}$ can be evaluated using analogy to bolted connections, according to (EN 1993-1-8 [14]):

$$
F_{c w, b}=2.5 \alpha f_{u, c w} d t_{c w}
$$

where $t_{c w}$ - thickness of column web; $d$ - bolt diameter (here replaced by the thickness of the tab $d=t_{\text {tab }}=4,0 \mathrm{~mm}$ ); $f_{u, c w}$ - ultimate tensile stress of column web; and $\alpha$ - reduction factor. In the case of joint with tabs, $\alpha=f_{u, c o} / f_{u, c w}=0.935$. Finally, the resistance of the column web in bearing can be predicted as $F_{c w, b}=8,07 \cdot 10^{3} \mathrm{~N}$.

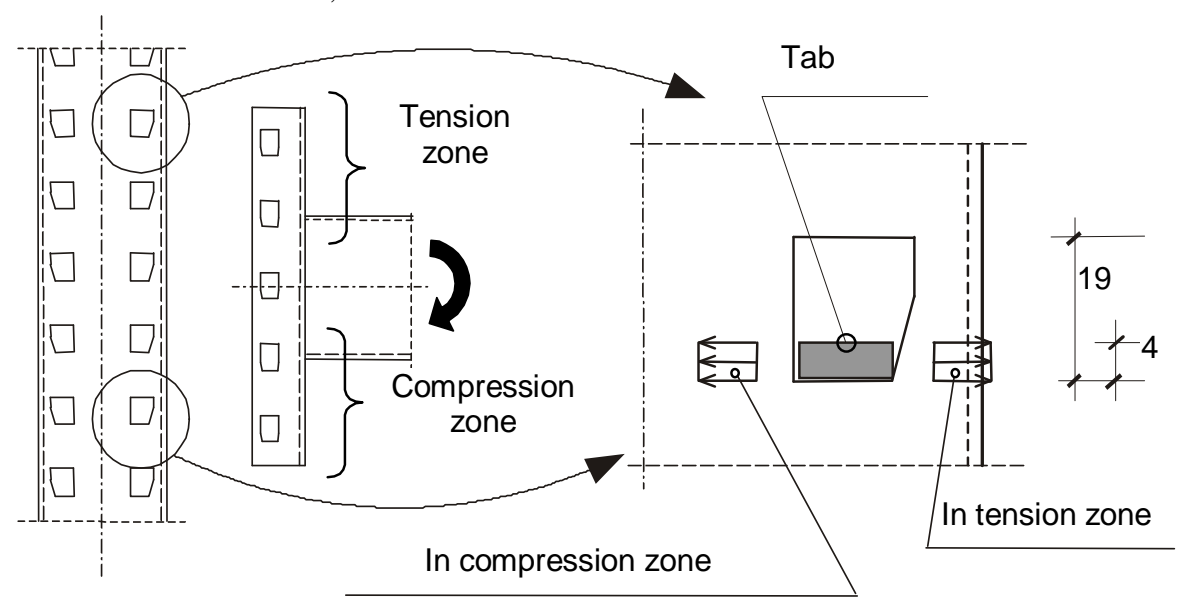

Figure 7. Local Stresses due to the Pressure Acting on the Hole Walls

The stiffness of the component $k_{c w, b}$ can be also estimated, as suggested by (EN 1993-1-8 [14]), for snug tightened bolts:

$k_{c w, b}=12 k_{b} k_{t} d f_{u, c w}$ 
where $d$ - bolt diameter (here replaced by the thickness of the tab $d=t_{t a b}=4,0 \mathrm{~mm}$ ); $f_{u, c w^{-}}$as above; $k_{b}, k_{t}$ - coefficients $\left(k_{b}=1,25 ; k_{t}=1,5 t_{c w} / d_{M 16} \leq 2,5\right)$. In Eq. (4) coefficient " 12 ” was used instead of "24", according to one row of the "bolts". Using the above equation, it can be found that $k_{c w, b}=48,5 \cdot 10^{2} \frac{\mathrm{N}}{\mathrm{mm}}$. The effect of local bearing stresses in compression zone is shown in Figure 8.

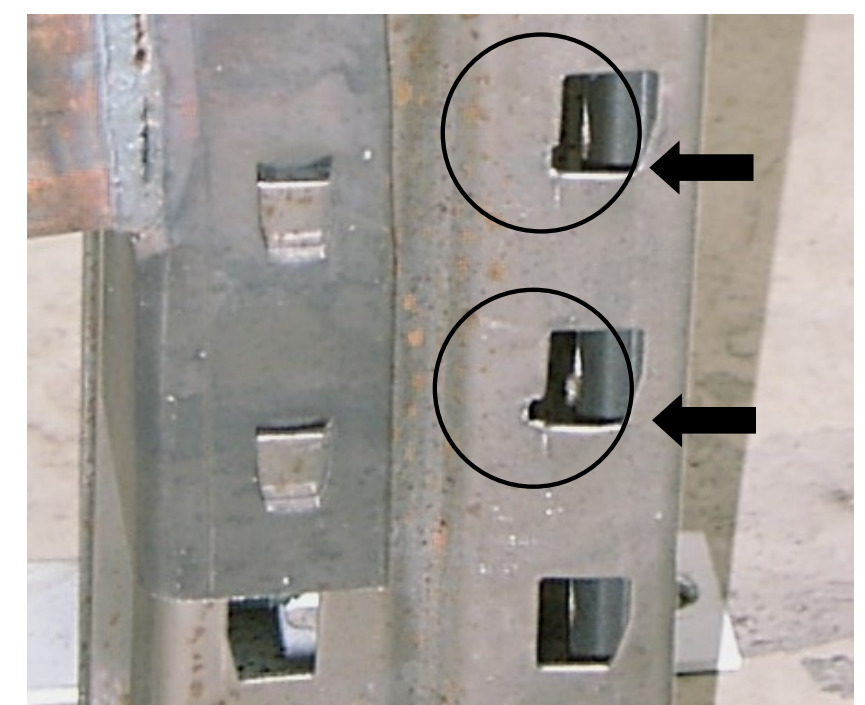

Figure 8. Effect of Bearing in Column Web Observed during the Tests

\subsubsection{Column web in tension (compression)}

A part of the column web is subjected to tension or compression (Fig. 9). The buckling resistance of the column web in compression can be computed according to (Chen and Newlin [17]) as:

$$
F_{c w, c}=10766.1 \frac{t_{c w}^{3}}{d_{w c}} \sqrt{f_{y, c w}}=42.2 \cdot 10^{3} \mathrm{~N}
$$

where $t_{c w}=$ thickness of column web, $d_{w c}=$ clear depth of column web, $f_{y, c w}=$ yield stress of column web.

The resistance of the tensioned part of the column web $F_{c w, t}$ can be determined according to (EN 1993-1-8 [14]) as:

$$
F_{c w, t}=\omega b_{\text {eff }} t_{c w} f_{y, c w}
$$

where $\omega$ - factor accounting for the interaction with shear, $b_{\text {eff }}$ - effective width of the web, $t_{c w}, f_{y, c w}$ - as above.

Assuming the tangent of the spreading angle 1:2.5 (Fig. 9), $b_{\text {eff }}=25+7.5=32.5 \mathrm{~mm}$ and $F_{C w, t}=25 \cdot 10^{3} N$.

The axial stiffness of the column web in tension and compression $k_{c w}$ can be evaluated by the relationship: 


$$
k_{c w}=E b_{e f f}^{\prime} t_{c w} / d_{w c}
$$

where $E$ - the elastic modulus, $t_{c w}, d_{w c}$ - as above.

The effective width $b_{\text {eff }}^{\prime}$ of the column web for stiffness calculation in the compression zone is equal to the length of the zone where distributed load from bearing is acting $(5.0 \mathrm{~mm})$. The effective width in the tension zone is predicted by considering an $45^{\circ}$ angle for the load spreading (Fig. 9). So, the axial stiffness in the compression zone is $k_{c w, c}=525 \cdot 10^{2} \frac{\mathrm{N}}{\mathrm{mm}}$ and in the tension zone is $k_{c w, t}=488 \cdot 10^{2} \frac{\mathrm{N}}{\mathrm{mm}}$. The local buckling of column web, in compression, observed during the tests is shown in Figure 10.

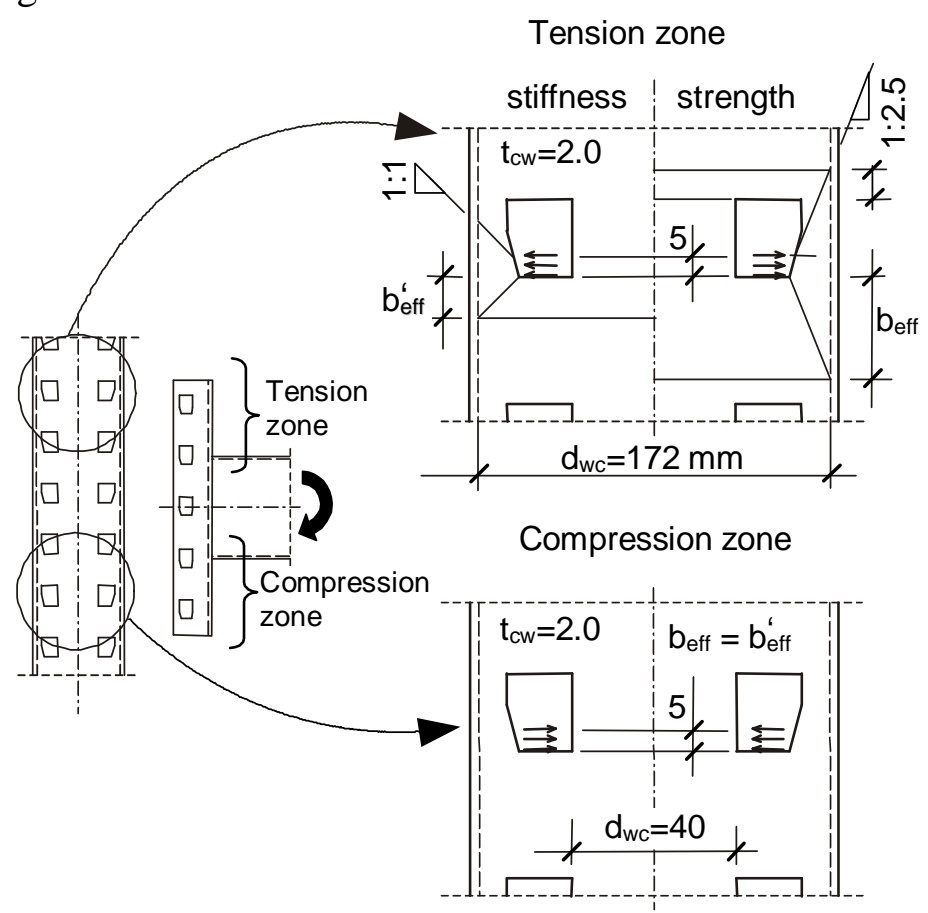

Figure 9. Model to Determine the Resistance and Stiffness of Column Web in Tension and Compression

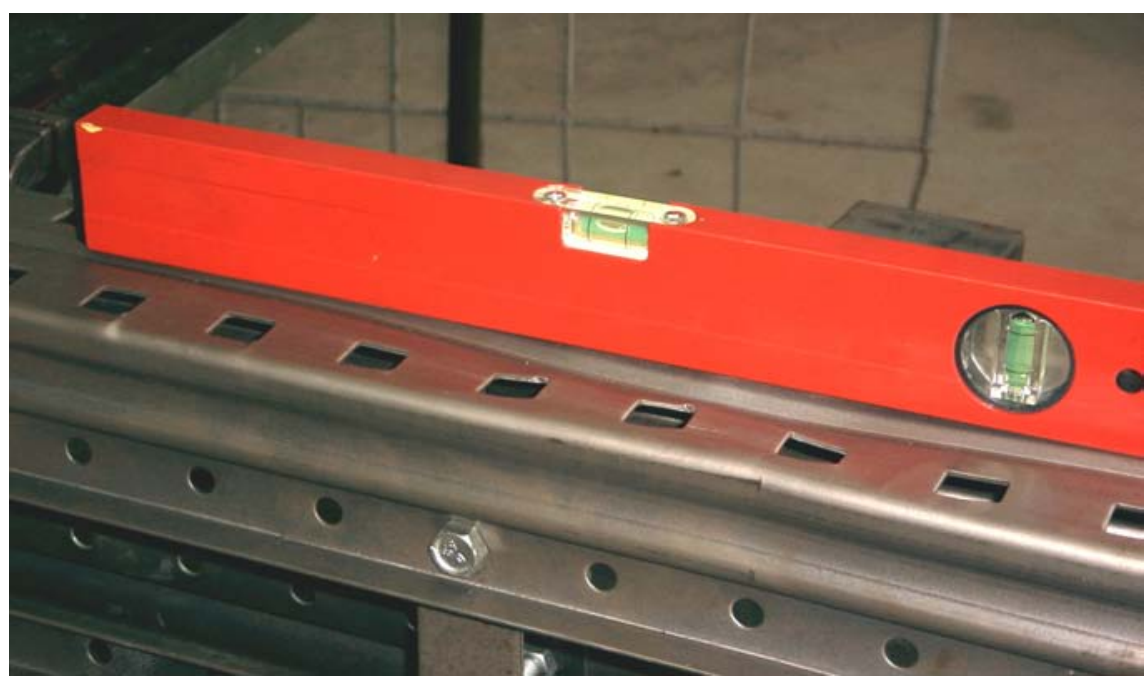

Figure 10. Local Buckling of Column Web in Compression Zone 


\subsubsection{Column web in shear}

Shear deformation of panel zone occurs only in case of external joints, when one-sided bending moment is acting from the beam. Shear force in panel zone is not uniformly distributed. Its values change in the levels of connector's tabs (or levels of perforations in columns), see Figure 11. The highest value of shear force is reached at the center of the panel zone, while a small reductions occurs at its ends. For the sake of simplicity, it can be assumed that the shear force is uniformly distributed in the entire panel zone. Transformation parameter $\beta$ accounting distribution of shear force at column length can in this case be calculated as (Faella et al. [18]):

$\beta=1-\frac{h_{p}}{h_{c}}$

where $h_{p}$ is the height of panel zone and $h_{c}$ is column height.

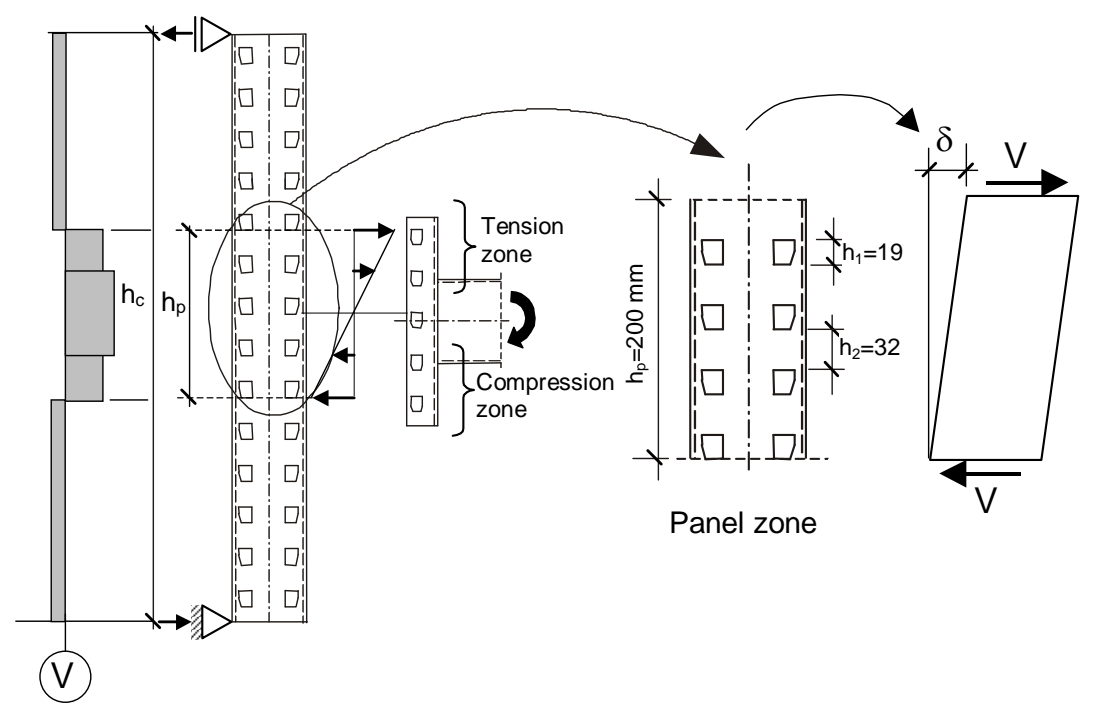

Figure 11. Panel Zone in Shear

The resistance of panel zone in shear including the effect of the distribution of shear force is given by:

$F_{c w, s}=\frac{V_{c w, s}}{\beta}$

where $V_{c w, s}$ - resistance of column web in shear:

$V_{c w, s}=\frac{f_{y, c w} A_{v c}}{\sqrt{3}}$

$A_{v c, n e t}$ is the shear area of column web, with accounting perforations of web. So the resistance of panel zone can be calculated as:

$F_{c w, s}=\frac{f_{y, c w} A_{v c}}{\beta \sqrt{3}}$ 
The height of panel zone is equal to $h_{p}=200 \mathrm{~mm}$, the column height in tested connections is equal to $h_{C}=570 \mathrm{~mm}$ and $A_{v c \text {,net }}=106 \mathrm{~mm}^{2}$, so $\beta=0.649$ and $F_{c w, s}=36,3 \cdot 10^{3} \mathrm{~N}$.

The stiffness of panel zone is affected by the presence of perforations at regular intervals at column height. The axial stiffness of spring modeling behavior of this component has to be predicted from general rule, (Fig. 11):

$k_{c w, s}=\frac{F}{\delta}$

Deflection of panel zone under shear deformation $\delta$ can be predicted as the sum of deformation of areas with net shear area $A_{v c, n e t}$ and with gross shear area $A_{v c}$ :

$\delta=\frac{F \sum h_{1}}{G A_{v c, \text { net }}}+\frac{F \sum h_{2}}{G A_{v c}}$

where $\sum h_{1}$ and $\sum h_{2}$ are the total height of net shear area and gross shear area respectively. Taking into account that $G=0.38 E$ and transformation parameter $\beta$ accounting distribution of shear force at column length, equation (12) can be written as follow:

$k_{c w, s}=\frac{0.38 E}{\beta\left(\frac{\sum h_{1}}{A_{v c, \text { net }}}+\frac{\sum h_{2}}{A_{v c}}\right)}$

which gives value of axial stiffness $k_{c w, s}=829,8 \cdot 10^{2} \mathrm{~N} / \mathrm{mm}$.

Deformation of panel zone observed during the tests is shown in Figure 12.

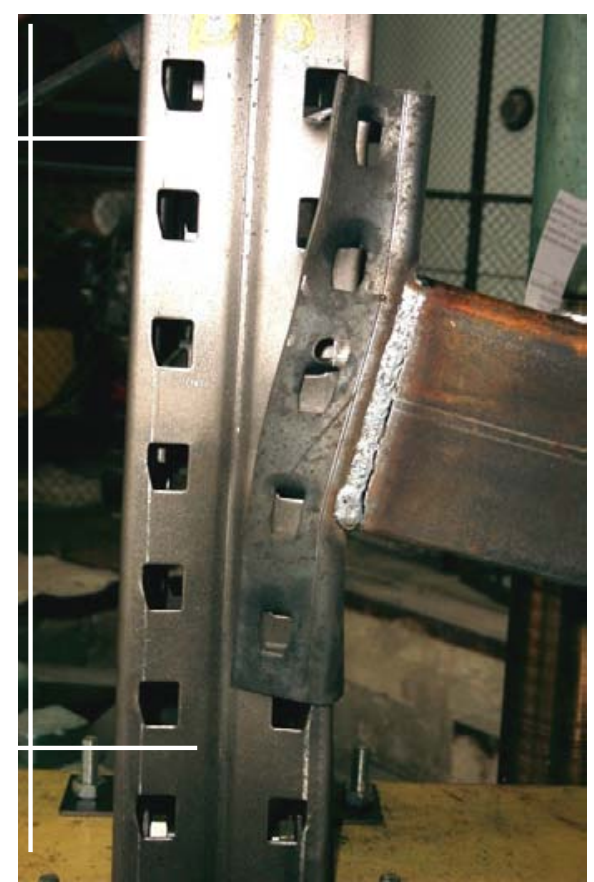

Figure 12. Deformation of Panel Zone 


\subsubsection{Tabs in shear}

Another component affecting the rotational behaviour of the rack joint is the tab of the connector, subjected to bending and shear from local bearing stresses. To predict the resistance and stiffness of this component, the model of a cantilever beam subjected to a concentrated load can be used (Fig. 13). The distance between the load and fixed end of beam, measured by the developed length of tabs is equal $l=7,0 \mathrm{~mm}$. The resistance of the tab $F_{t, s}$ can be evaluated as shear resistance:

$$
F_{t, s}=A_{v}\left(f_{u, c o} /\right.
$$

where $A_{V}$ - effective shear area of tab; $f_{u, c o}$ - ultimate tensile stress of connector.

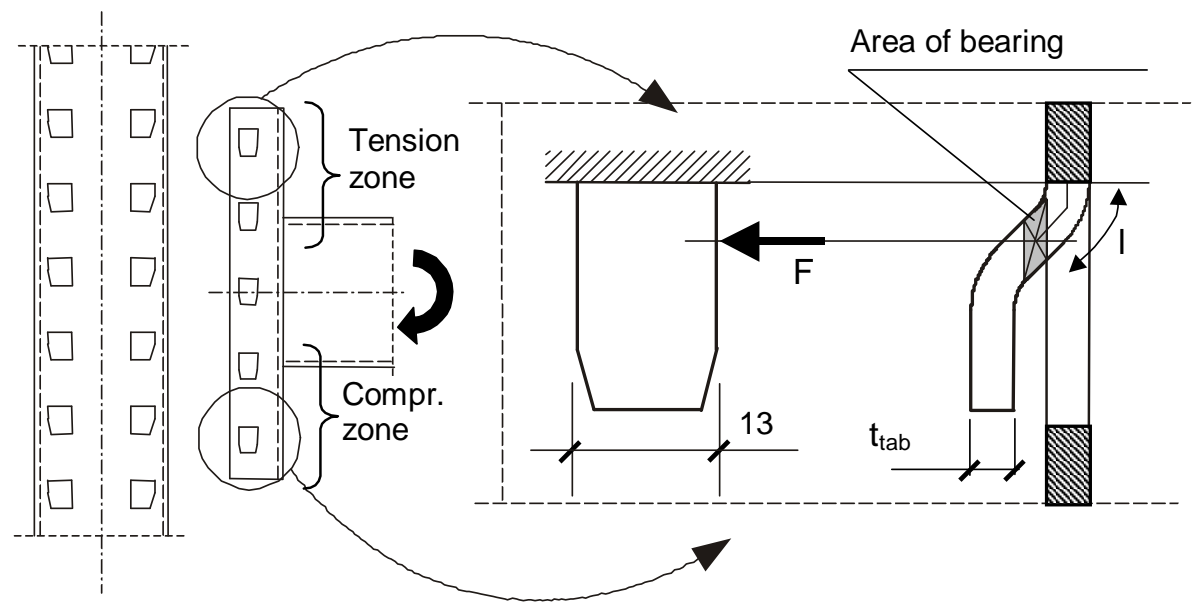

Figure 13. Tab in Shear and Bending

Because of the existence of undercuts in tabs, made during punching in time of production, effective thickness of tabs is equal $t_{t a b \text {,eff }}=3,0 \mathrm{~mm}$, instead the nominal value $t_{\text {tab, nom }}=4,0 \mathrm{~mm}$. The resistance is based on the ultimate tensile strength of the connector $f_{u, c o}$ rather than the yield stress, so resistance of the component can be calculated as $F_{t, s}=9,1 \cdot 10^{3} \mathrm{~N}$.

The initial stiffness of this component $k_{t, s}$ can be calculated using equation (2), where $\delta$ is the deflection of the beam (at the point where the concentrated load $F$ is acting) from bending and shear:

$$
\delta=\left(\frac{l^{3}}{3 E I}+\frac{1.2 l}{G A_{V}}\right) F
$$

Both moment of inertia $I$ and shear area $A_{V}$ should be calculated taking into account the effective thickness of the tabs. Using above equations, it can be predicted that $k_{t, s}=2714 \cdot 10^{2} \frac{\mathrm{N}}{\mathrm{mm}}$. This component is active both in the tension and compression zones of the joint. 
Deformations of tabs, due to shear and bending, observed during the tests are depicted in Figure 14.

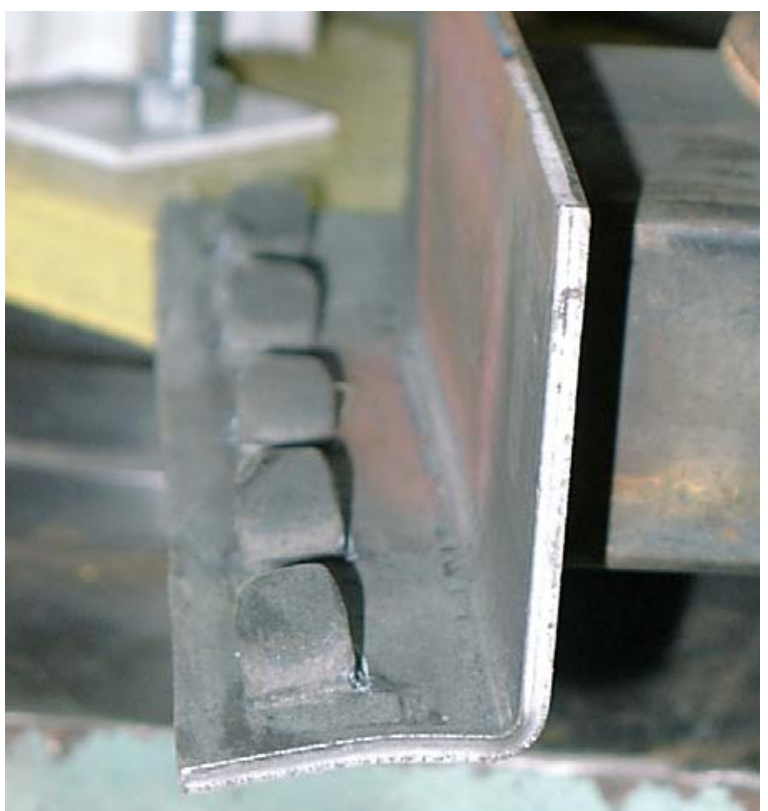

Figure 14. Deformation of Tabs due to Shear and Bending

\subsubsection{Connector in bending and shear}

Behaviour of the connector can be modelled taking into account a cantilevered part of the connector, protruding over the flange surface of the beam, as shown in Figure 15.
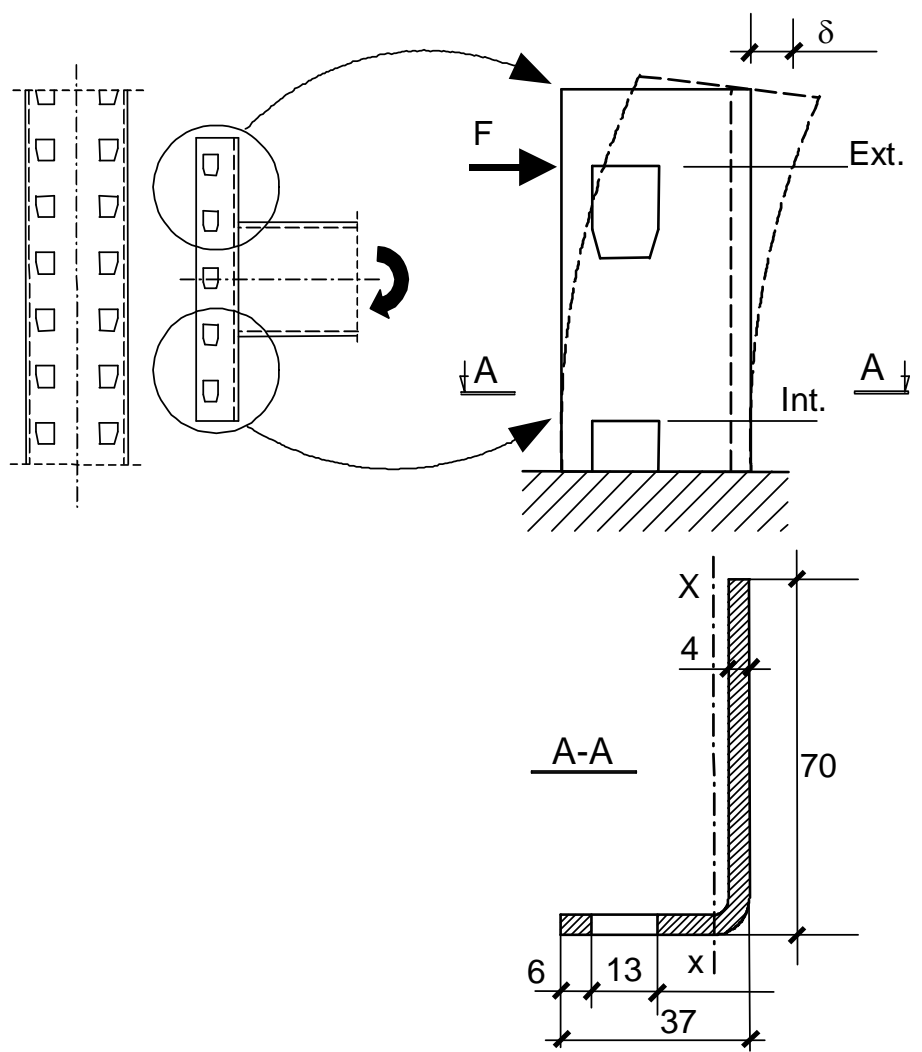

Figure 15. Connector in Bending and Shear 
Resistance of the component can be found as plastic resistance of an element subjected to bending and shear:

$$
\begin{aligned}
& V_{c o, s}=A_{V} f_{y, c o} / \sqrt{3}=19,2 \cdot 10^{3} \mathrm{~N} \\
& M_{c o, b}=W_{p l} f_{y, c o}=42,22 \cdot 10^{4} \mathrm{~N} \mathrm{~mm} .
\end{aligned}
$$

where $A_{V}$ - effective shear area of connector; $f_{y, \text { co }}$ - yield stress of connector; $W_{p l^{-}}$plastic section modulus of connector.

The initial stiffness $k_{c o}$ of this component is calculated as the ratio of the force to the deflection of the component under this force, equation (2). Because of the openings (slots) in connector, the deflection of the component was evaluated as for shear-wall structures containing openings under lateral loads according to (Benjamin [19]), including the effects of bending and shear. Every tested group of joints has different beam heights, so the initial stiffness of the component is different for each group. In every group, two values of initial stiffness have been calculated: for external slot (force is acting in tab more distant to the beam), and for internal slot (force is acting in tab closer to the beam). Predicted values of the initial stiffness for each group are listed below.

$$
\begin{array}{ll}
\text { Group “B”: } & k_{c o, \text { ext }}=540 \cdot 10^{2} \frac{\mathrm{N}}{\mathrm{mm}}, \quad k_{c o, \text { int }}=5664 \cdot 10^{2} \frac{\mathrm{N}}{\mathrm{mm}} ; \\
\text { Group “C”: } & k_{c o, \text { ext }}=368 \cdot 10^{2} \frac{\mathrm{N}}{\mathrm{mm}}, \quad k_{c o, \text { int }}=2689 \cdot 10^{2} \frac{\mathrm{N}}{\mathrm{mm}} ; \\
\text { Group “E”: } & k_{c o, \text { ext }}=662 \cdot 10^{2} \frac{\mathrm{N}}{\mathrm{mm}}, \quad k_{c o, \text { int }}=\infty .
\end{array}
$$

For group " $D$ " the values of initial stiffness of connector in bending and shear are the same as in group “B”, and for group " $F$ ” as in group “E”.

This component is active both in the tension and compression zones of the joint. Observed deformations of connector during the test are shown in Figure 16.

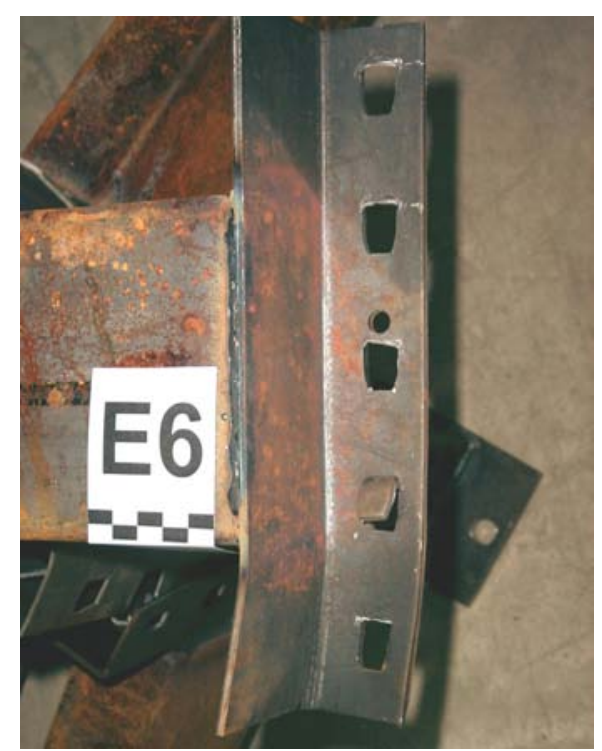

Figure 16. Deformation of Connector Observed during the Tests 


\subsubsection{Connector web in tension (compression)}

Regarding the tension and compression zones of the connector web, the resistance $F_{\text {cow }}$ can be estimated according to (EN 1993-1-8 [14]) as:

$$
F_{\text {cow }}=\omega b_{\text {eff }} t_{c o} f_{y, c o}
$$

where $\omega$ - factor accounting for the interaction with shear; $t_{c o}$ - thickness of the connector's web, $f_{y, c w}$ - yield stress of connector. The effective width of the connector web $b_{\text {eff }}$ accounts for the spreading of the stresses transmitted by the beam flange (Figure 17). Assuming the tangent of the spreading angle 1:2.5, $b_{\text {eff }}=27 \mathrm{~mm}$ can be adopted and the resistance in compression and tension zones can be calculated as

$$
F_{\text {cow }, t}=F_{\text {cow }, c}=37,4 \cdot 10^{3} \mathrm{~N} \text {. }
$$
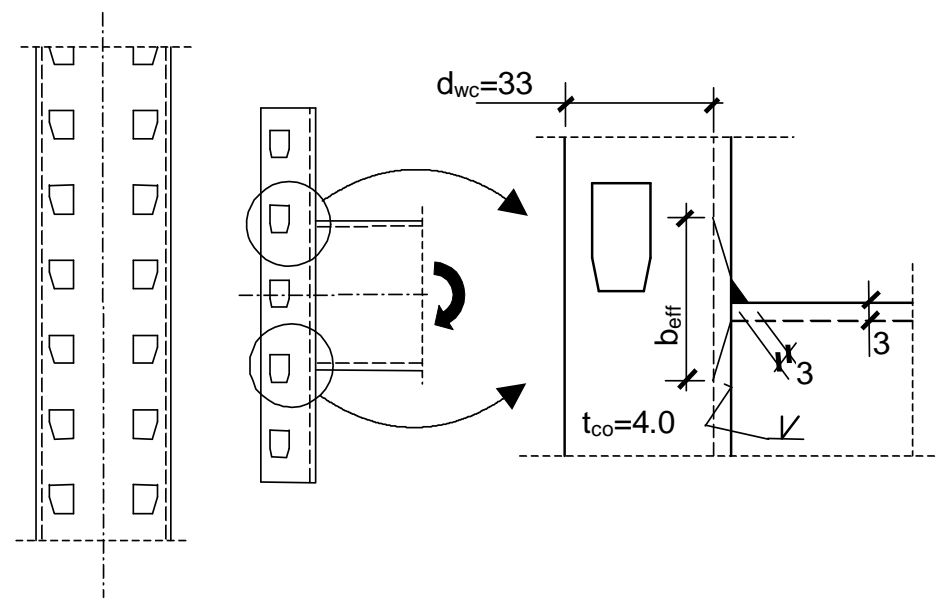

Figure 17. Connector Web in Tension or in Compression

The axial stiffness of the connector web in tension and compression can be evaluated from the relationship:

$$
k_{c o w}=E b_{e f f}^{\prime} t_{c o} / d_{w c}
$$

Assuming an angle of $45^{\circ}$ for the load spreading, the value of the initial stiffness $k_{\text {cow }, t}=k_{\text {cow }, c}=5760 \cdot 10^{2} \frac{\mathrm{N}}{\mathrm{mm}}$ can be calculated.

\subsubsection{Beam flange in tension (compression)}

The last component, beam flange in tension and compression, has to be considered only in the evaluation of the joint resistance. Its resistance can be computed as:

$$
F_{b f, c}=F_{b f, t}=b_{e f f} t_{b f} f_{y, b f}
$$


where $t_{b f}$ - thickness of the beam flange, $f_{y, b f}$ - yield stress of beam flange. The spreading of stresses to calculate the effective width of the beam $b_{\text {eff }}$ is depicted in Figure 18. The value of resistance in tension and compression zone can be predicted as $F_{b f, c}=F_{b f, t}=29,9 \cdot 10^{3} \mathrm{~N}$.
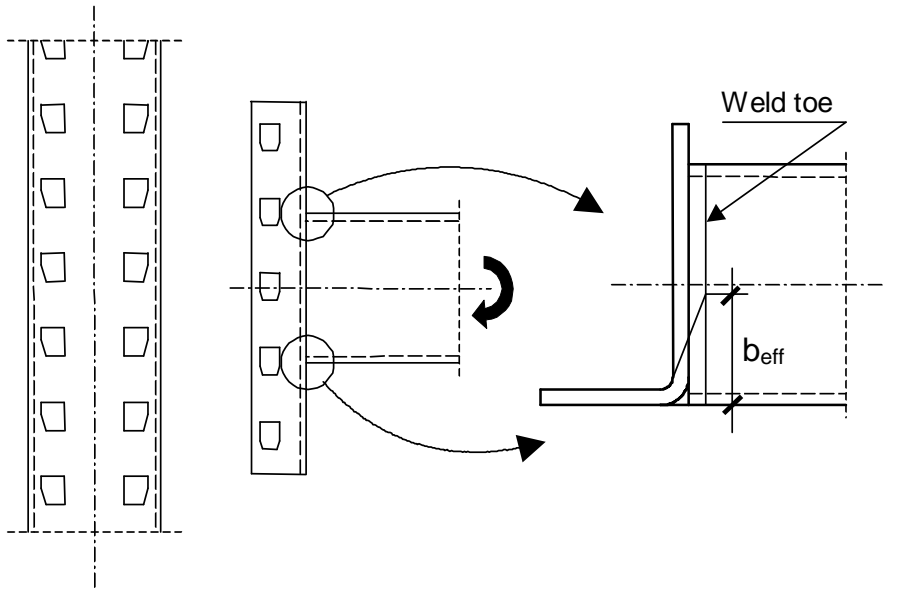

Figure 18. Stress Distribution in the Beam Flange

\subsection{Evaluation of the Rotational Stiffness}

The mechanical model adopted to predict the initial rotational stiffness is shown in Figure 19a. The springs representing the behaviour of the components are located at the level of the tabs of connector and at the level of beams flange. Only the lever arm of spring representing behaviour of panel zone is different. According to (EN 1993-1-8 [14]), it can conservatively be taken as the distance from centre of compression to a point midway between two rows of tabs in tension zone. In the calculation, it is also assumed that the contribution of the springs situated in the centre part of the joint is small and so their influence has been neglected.

a)

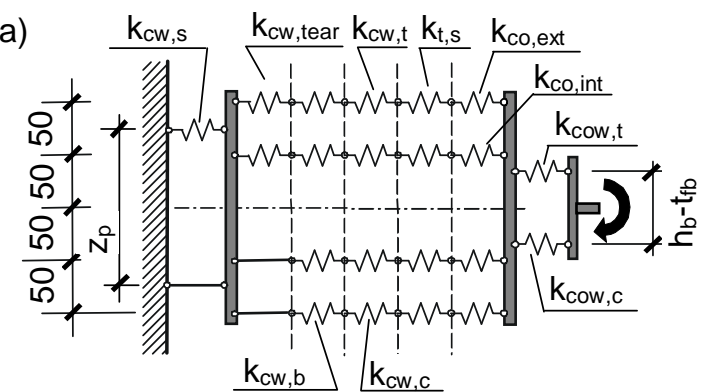

c)

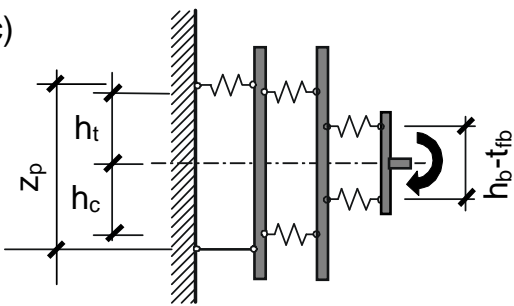

b)

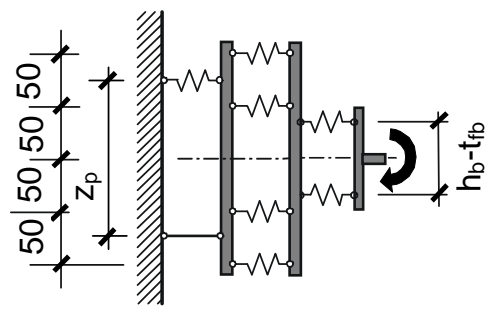

e)

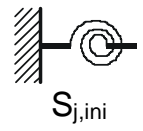

Figure 19. Mechanical Model and Procedure for Evaluating the Rotational Stiffness 
The procedure to evaluate the rotational stiffness is depicted in Figures 19b - 19e. The first step is the computation of effective stiffness of each row (Fig. 19b), followed by the prediction of the equivalent overall stiffness in the compression and tension zones and of the lever arms (Fig. 19c). Third step is the change of two springs with axial stiffness into one spring with rotational stiffness (Fig. 19d); and finally the prediction of the initial stiffness of the whole model, (Fig. 19e). Adequate relationships to make conversion of mechanical model from Figure 19a to model depicted in Figure 19e can be found in mechanics handbooks or in (Faella et al. [18]). Presented model is general, spring representing panel behaviour is only active in external connections. In internal connections, panel zone is not affected by shear force and $k_{c w, s}=\infty$.

The most influencing component on the rotational stiffness in tested connections is the column web in bearing.

\subsection{Evaluation of the Flexural Resistance}

Behaviour of such joints can be considered in two stages: before direct contact of connector with column flange (elastic stage) and after this contact occurred (plastic stage).

Mechanical model adopted to predict the elastic flexural resistance and lever arms for each group of components are presented in Figure 20a. Because the weakest component governs the resistance of each row, model depicted in Figure 20a can be easily simplified into model presented in Figure 20b.

a)

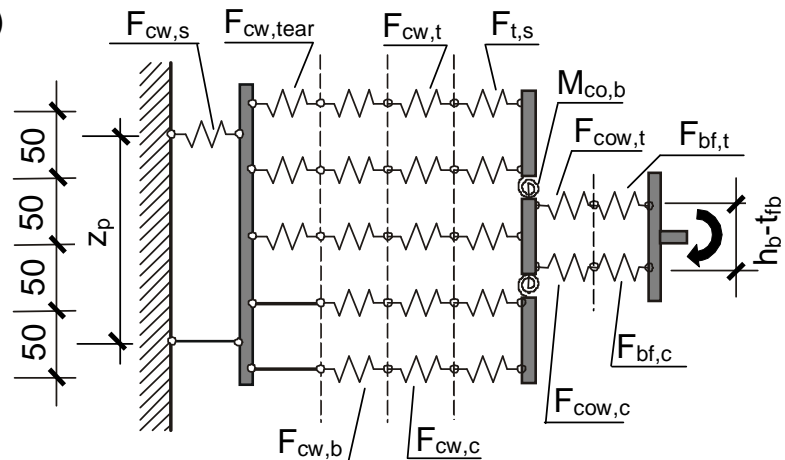

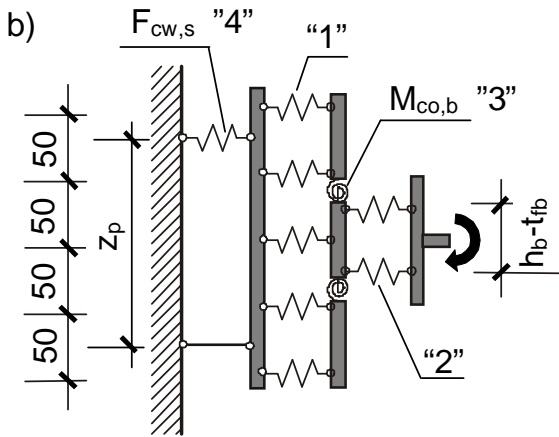

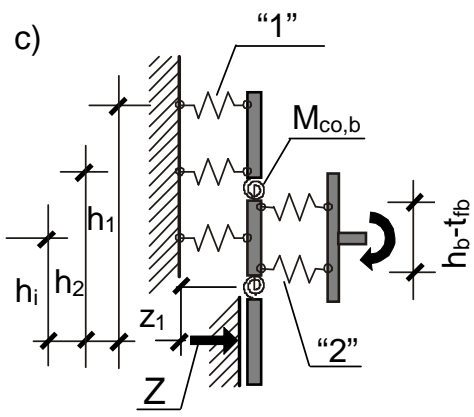

Figure 20. Mechanical Models for the Elastic and Plastic Flexural Resistance Evaluation

The resistance of components marked " 1 " in Figure $20 \mathrm{~b}$ is equal to $F=F_{c w \text {,tear }}=6,36 \cdot 10^{3} \mathrm{~N}$ when component is in tension (column web in tearing), or $F=F_{c w, b}=8,07 \cdot 10^{3} N$ when component is in compression (column web in bearing). The resistance of components marked "2" (beam flange) is equal $F=F_{b f, c}=F_{b f, t}=29,9 \cdot 10^{3} N$ and the resistance of the connector in 
bending (modelled as rotational spring " 3 ”) is equal to $M_{c o, b}=42,22 \cdot 10^{4} \mathrm{~N} \mathrm{~mm}$. The resistance of column web in shear (" 4 ") is equal to $F_{c w, s}=36,3 \cdot 10^{3} N$, but this component should be considered only in case of external connections. In internal connections, panel zone is not affected by shear force and $F_{c w, s}=\infty$. Model presented in Figure 20b represents only the initial behaviour of joint when the gap between the column flange and connector (Fig. 2) still exists.

To describe ultimate behaviour of connection, it can be assumed that the rotation of the connector increases, the gap disappears and contact stresses start acting between column flange and connector directly, (Fig. 20c), what change the lever arm. Also, it is assumed that plastic distribution of internal forces can be obtained - the tests (Kozłowski and Ślęczka [13]) showed that all components have proper ductility. All forces acting in each row of components " 1 " in tension zone reach plastic capacity: minimum value between the resistance of their basic components $F=F_{c w \text {,tear }}=6,36 \cdot 10^{3} \mathrm{~N}$ (column web in tearing). From condition of equilibrium, the reaction in compression zone $Z$ is equal to the sum of forces in each tension rows. When the gap has disappeared, bearing stresses between connector and column are non-uniformly distributed. Because the flexural resistance of connector protruding over the flange surface of the beam cannot be exceeded, the centre of compression can be determined from equation:

$$
z_{1}=\frac{M_{c o, b}}{Z}
$$

where $Z=$ reaction force in compression zone, $M_{c o, b}=$ flexural resistance of connector and $z_{1}$ = distance of centre of compression from bottom flange of beam, see Figure 20c. When the centre of compression is found, plastic flexural resistance can be predicted using equation:

$$
M_{p l}=F_{c w, t e a r} \sum_{i=1}^{3} h_{i}+M_{c o, b}
$$

where $h_{i}=$ the distance of $i$-th component from the centre of compression, $F_{c w, t e a r}=$ minimum value of the resistance in each row (in this case column web in tearing) and $M_{c o, b}=$ flexural resistance of connector. In addition, the flexural resistance of upper part of connector should be checked. When the bending moment generated by two forces acting in upper rows is greater than the value of force acting in upper row, then the flexural resistance of connector $M_{c o, b}$ should be reduced to a value of $\psi F_{c w \text {,tear }}$ in order to satisfy moment equilibrium. In case of external connections, plastic flexural resistance of connection could not be greater than the resistance of column web in shear: $M_{p l} \leq F_{c w, s} z_{p}$. Figure 20c shows configurations of components only in internal connections.

Component method shows that plastic flexural resistance of most joints (group "B", "D", "E” and "F") is governed by the resistance of column web in tearing $F_{c w \text {,tear }}$ in tension zone and connector in bending and shear $M_{c o, b}$ in compression zone (Figure 21). Only in case of group "C", the moment resistance is influenced by flexural resistance of connector $M_{c o, b}$ in tension zone, giving reduction of the force acting in the first row to $\psi F_{c w, t e a r}$ (Figure 21). 

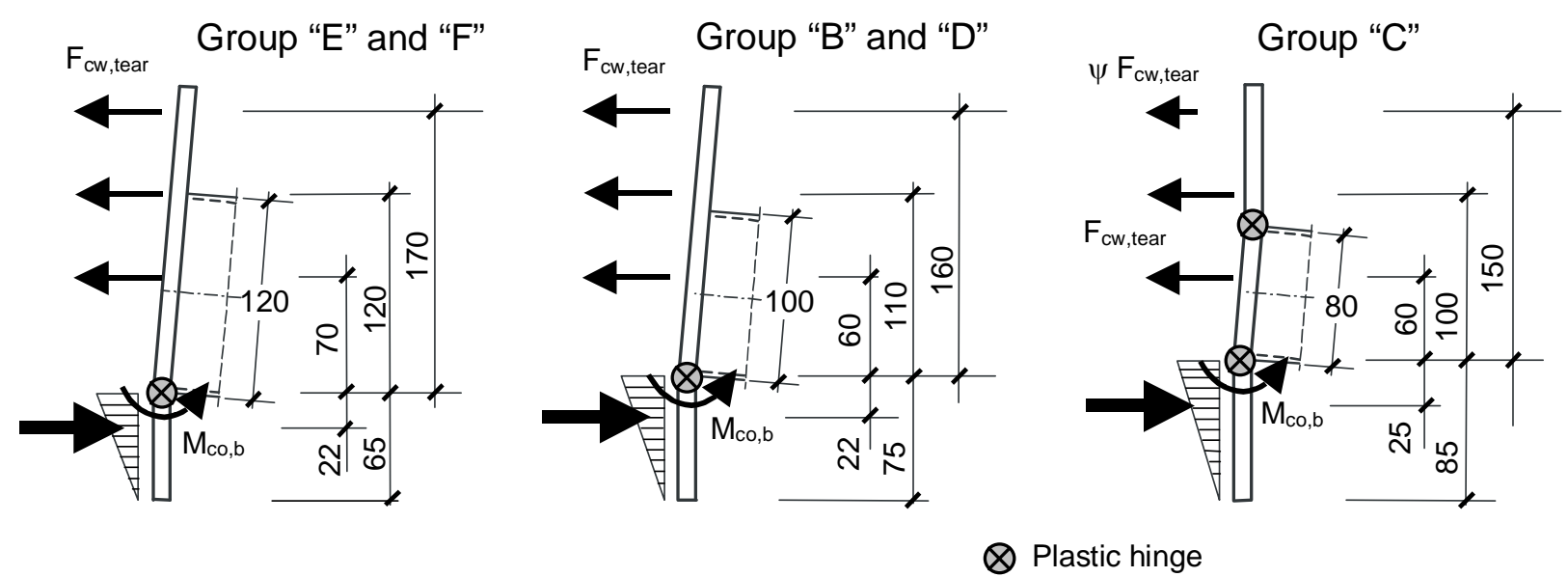

Figure 21. Plastic Resistance Model of Each Tested Joint Group

\section{COMPARISON OF RESULTS}

Deformations of internal connectors observed during the tests are depicted in Figure 22 to compare with these from the proposed models, as shown in Figure 21.

Collection of the resistances and stiffness of basic components, obtained using component method, is presented in Table 4. It can be seen that the weakest component in tension zone is column web in tearing, which the resistance is only $F_{c w, t e a r}=6,36 \cdot 10^{3} N$. In compression zone, the weakest is column web in bearing: $F_{c w, b}=8,07 \cdot 10^{3} N$. The biggest influence on the joint global stiffness is the bearing of the tab to column web. These findings were confirmed during experimental tests and by the failure modes of joints, see Figures 6 and 8.
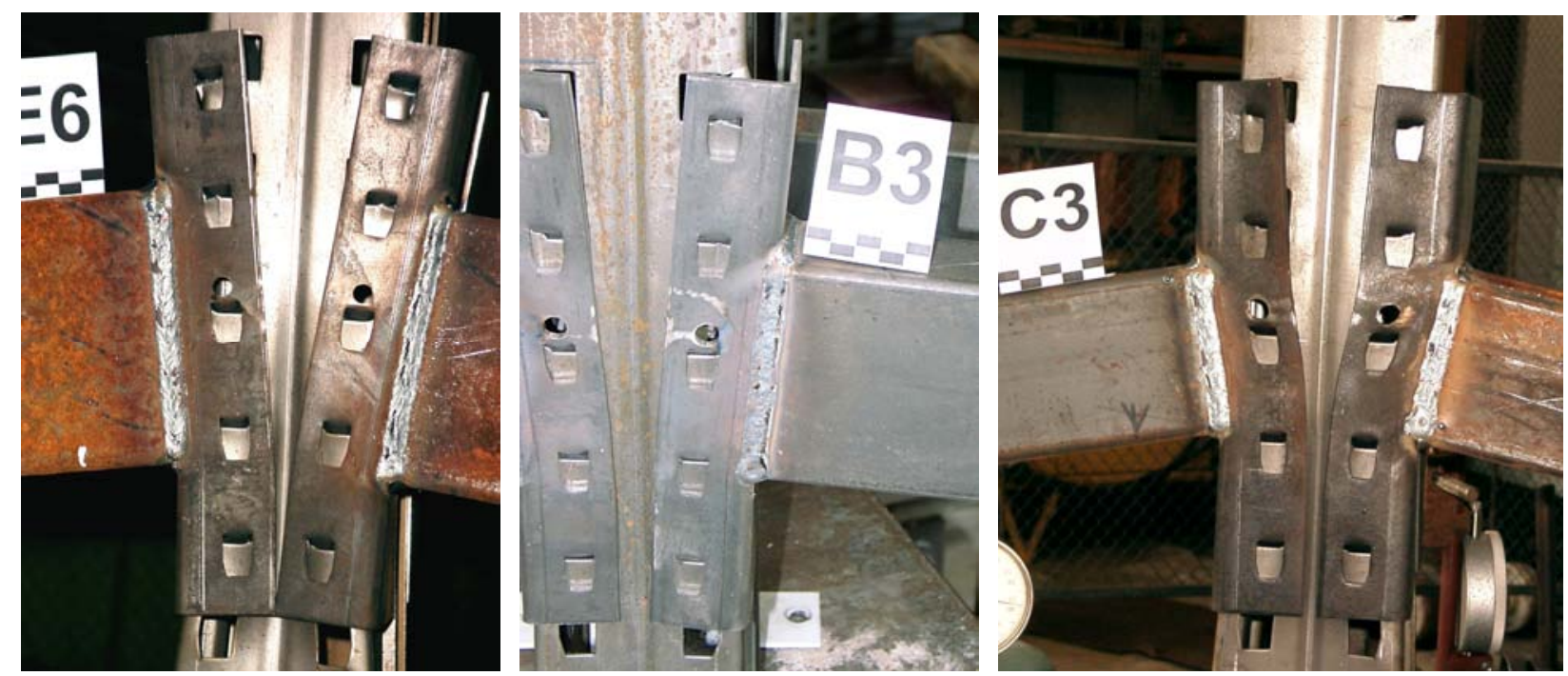

Figure 22. Typical Deformation of Internal Joints Observed in Each Joint Group 
Table 4. Stiffness and Resistance of Analysed Joint Components

\begin{tabular}{|c|c|c|c|c|}
\hline \multicolumn{2}{|c|}{ Component } & Axial stiffness & $\frac{N}{m m}$ & Resistance $[N],[\mathrm{Nmm}]$ \\
\hline \multicolumn{2}{|c|}{ Column web in tearing } & \multicolumn{2}{|c|}{$k_{c w, \text { tear }}=5599 \cdot 10^{2}$} & $F_{c w, \text { tear }}=6,36 \cdot 10^{3}$ \\
\hline \multicolumn{2}{|c|}{ Column web in bearing } & \multicolumn{2}{|l|}{$k_{c w, b}=48,5 \cdot 10^{2}$} & $F_{c w, b}=8,07 \cdot 10^{3}$ \\
\hline \multicolumn{2}{|c|}{ Column web in tension } & \multicolumn{2}{|l|}{$k_{c w, t}=488 \cdot 10^{2}$} & $F_{c w, t}=25 \cdot 10^{3}$ \\
\hline \multicolumn{2}{|c|}{$\begin{array}{l}\text { Column web in } \\
\text { compression }\end{array}$} & \multicolumn{2}{|l|}{$k_{c w, c}=525 \cdot 10^{2}$} & $F_{c w, c}=42,2 \cdot 10^{3}$ \\
\hline \multicolumn{2}{|c|}{ Column web in shear } & \multicolumn{2}{|l|}{$k_{c w, s}=829,8 \cdot 10^{2}$} & $F_{c w, s}=36,3 \cdot 10^{3}$ \\
\hline \multicolumn{2}{|c|}{ Tabs in shear } & \multicolumn{2}{|l|}{$k_{t, s}=2714 \cdot 10^{2}$} & $F_{t, s}=9,1 \cdot 10^{3}$ \\
\hline \multirow{6}{*}{$\begin{array}{l}\text { Connector } \\
\text { in } \\
\text { bending } \\
\text { and shear }\end{array}$} & \multirow{2}{*}{$\begin{array}{l}\text { Group “B” } \\
\text { and “D” }\end{array}$} & \multicolumn{2}{|l|}{$k_{c o, e x t}=540 \cdot 10^{2}$} & \multirow{6}{*}{$\begin{array}{l}V_{c o, s}=19,2 \cdot 10^{3} \\
M_{c o, b}=42,22 \cdot 10^{4}\end{array}$} \\
\hline & & $k_{c o, i n t}=5664 \cdot 10^{2}$ & & \\
\hline & \multirow{2}{*}{ Group “C” } & \multicolumn{2}{|l|}{$k_{c o, e x t}=368 \cdot 10^{2}$} & \\
\hline & & \multicolumn{2}{|l|}{$k_{\text {co,int }}=2689 \cdot 10^{2}$} & \\
\hline & \multirow{2}{*}{$\begin{array}{l}\text { Group “E” } \\
\text { and "F" }\end{array}$} & \multicolumn{2}{|l|}{$k_{c o, e x t}=662 \cdot 10^{2}$} & \\
\hline & & \multicolumn{2}{|l|}{$k_{c o, i n t}=\infty$} & \\
\hline \multicolumn{2}{|c|}{$\begin{array}{l}\text { Connector web in } \\
\text { tension (compression) }\end{array}$} & \multicolumn{2}{|c|}{$k_{\text {cow }, t}=k_{\text {cow }, c}=5760 \cdot 10^{2}$} & $F_{\text {cow }, t}=F_{\text {cow,c }}=37,4 \cdot 10^{3}$ \\
\hline \multicolumn{2}{|c|}{$\begin{array}{l}\text { Beam flange in tension } \\
\text { (compression) }\end{array}$} & \multicolumn{2}{|c|}{-} & $F_{b f, c}=F_{b f, t}=29,9 \cdot 10^{3}$ \\
\hline
\end{tabular}

Comparison of predicted by component method values of initial rotational stiffness with values from tests is shown in Table 5. Analytical values of plastic flexural resistance $M_{p l}$ for all analysed groups and their comparison to values obtained during experimental tests are presented in Table 6.

Table 5. Prediction of the Initial Stiffness and Comparison with Experimental Data

\begin{tabular}{|l|c|c|c|}
\hline & $\begin{array}{c}\text { Test results } \\
{[\mathrm{kNm} / \mathrm{rad}]}\end{array}$ & $\begin{array}{c}\text { Component method } \\
{[\mathrm{kNm} / \mathrm{rad}]}\end{array}$ & $\begin{array}{c}\text { Difference: } \\
\text { (component-test)/test } \\
{[\%]}\end{array}$ \\
\hline Group “B” & 139,40 & 98,2 & $-29,6$ \\
Group “C” & 116,70 & 93,6 & $-19,8$ \\
Group “D” & 71,35 & 93,3 & 30,7 \\
Group “E” & 123,06 & 100,4 & $-18,4$ \\
Group “F” & 96,15 & 95,3 & $-0,8$ \\
\hline
\end{tabular}


Table 6. Prediction of the Plastic Flexural Resistance and Comparison with Experimental Data

\begin{tabular}{|l|c|c|c|}
\hline & $\begin{array}{c}\text { Test results } \\
{[\mathrm{kNm}]}\end{array}$ & $\begin{array}{c}\text { Component method } \\
{[\mathrm{kNm}]}\end{array}$ & $\begin{array}{c}\text { Difference: } \\
\text { (component-test)/test } \\
{[\%]}\end{array}$ \\
\hline Group "B" & 3,19 & 2,95 & $-7,5$ \\
Group “C” & 2,36 & 2,49 & 5,5 \\
Group "D" & 3,10 & 2,95 & $-4,8$ \\
Group "E” & 3,20 & 3,13 & $-2,2$ \\
Group "F" & 3,37 & 3,13 & $-7,1$ \\
\hline
\end{tabular}

Comparisons of predicted by means of the component method results with those obtained from tests shows the high level of accuracy, both for the stiffness and for the flexural resistance, in case of analysed joints.

\section{CONCLUSIONS}

Behaviour of pallet rack joints is governed by a few components. Some of them are very similar to the components in structural connections of hot rolled I and H sections: column web in shear, column web in tension or in compression, beam flange in tension or in compression. Others are the result of using cold-formed perforated columns, special connectors and tabs in beam-column connection: tabs in shear, connector in bending and shear and column web in tearing. Analysis of behaviour of particular basic parts of the joints, like in component method, enable designers to understand joint performance and safety design.

Next advantage of the component method is the possibility to predict mechanical characteristics of joints without expensive experimental work. Traditionally, the behaviour of such complex joints as steel pallet rack joints is predicted by testing. The component approach presented in the paper can be used as complementary method.

Next important advantage of the component method is the possibility to provide clear and precise specification of the influence of each component on the resistance and stiffness of the joint. The weakest component can be easily identified and improved. It makes easier to conduct the optimisation of joints, especially in the systems, which are produced in long series, as steel storage pallet racks.

Level of accuracy attained from component method shows the possibility of using this method in practical application. 


\section{REFERENCES}

[1] Abdel-Jaber, M., Beale, R.G., Godley, M.H.R, "Numerical Study on Semi-rigid Racking Frames under Sway”, Computers and Structures, 2005, Vol. 83, pp. 2463-2475.

[2] Beale, R.G., Godley, M.H.R., "Sway Analysis of Spliced Pallet Rack Structures", Computers and Structures, 2004, Vol. 82, pp. 2145-2156.

[3] Bernuzzi, C., Castiglioni, C.A., "Experimental Analysis on the Cyclic Behaviour of Beam-to-column Joints in Steel Storage Pallet Racks”, Thin-Walled Structures, 2001, Vol. 39, pp. 841-859.

[4] Freitas, A.M.S., Freitas, M.S.R., Souza, F.T., “Analysis of Steel Storage Rack Columns”, Journal of Constructional Steel Research, 2005, Vol. 61, No. 1135-1146.

[5] Godley, M.H.R., Beale, R.G., Feng, X., "Analysis and Design of Down-aisle Pallet Rack Structures”, Computers and Structures, 2000, Vol. 77, pp. 391-401.

[6] Peköz, T., Rao, K., "Design of Industrial Storage Racks”, Progress in Structural Engineering and Materials, 2001, Vol. 3, pp. 28-35.

[7] The, L.H., Hancock, G.J., Clarke, M.J., "Analysis and Design of Double-Sided High-Rise Steel Pallet Rack Frames”, Journal of Structural Engineering, July 1 2004, Vol. 130, No. 7, pp. 1011-1021.

[8] Baldassino, N., Zandonini, R., "Design by Testing of Steel Storage Pallet Racks", Proceedings of the $3^{\text {rd }}$ European Conference on Steel Structures, Coimbra, 2002, Vol. 1, pp. 689-698.

[9] Baldassino, N., Bernuzzi, C., “Analysis and Behaviour of Steel Storage Pallet Racks”, Thin-Walled Structures, 2000, Vol. 37, pp. 277-304.

[10] Markazi, F.D., Beale, R.G., Godley, M.H.R., "Experimental Analysis of Semi-Rigid Boltless Connectors”, Thin-Walled Structures, 1997, Vol. 28, No.1, pp. 57-87.

[11] Markazi, F.D., Beale, R.G., Godley, M.H.R., "Numerical Modelling of Semi-rigid Boltless Connectors”, Computers and Structures, 2001, Vol. 79, pp. 2391-2402.

[12] Institute of Logistics and Warehousing, "Safety of Storage Systems. Freestanding Racks. Basic requirements”, IL-B-001:1998 (in Polish).

[13] Kozłowski, A., Ślęczka, L., "Experimental Analysis of Beam-to-column Joints in Steel Storage Pallet Racks", Proceedings of the $3^{\text {rd }}$ European Conference on Steel Structures, Coimbra, 2002, Vol. II, pp. 897-906.

[14] EN 1993-1-8, Eurocode 3: Design of Steel Structures - Part 1.8: Design of Joints. CEN, Brussels, 2005.

[15] EN 1994-1-1. Eurocode 4: Design of Composite Steel and Concrete Structures. Part 1.1: General Rules and Rules for Buildings. CEN, Brussels, 2002.

[16] Fink, J., Rubin, D., Hollmann, K., “Anwendung des Innsbrucker Komponentenmodells bei der Optimierung eines modernen Deckenschaltischs“, Stahlbau 72, 2003, Heft 1.

[17] Chen, W.F., Newlin, D.E., "Column Web Strength of Beam-to-Column Connections”, Journal of the Structural Division, ASCE, 1973, Vol. 99, No. ST9.

[18] Faella, C., Piluso, V., Rizzano, G., "Structural Steel Semi rigid Connections, Theory, Design and Software”, CRC Press, 2000.

[19] Benjamin, J. R., “Statically Indeterminate Structures”, McGRAW-HILL, 1959. 